NASA/CR-2002-211515

\title{
Computation of Turbulent Heat Transfer on the Walls of a 180 Degree Turn Channel With a Low Reynolds Number Reynolds Stress Model
}

A.A. Ameri

University of Toledo, Toledo, Ohio

D.L. Rigby

QSS Group, Inc., Cleveland, Ohio

E. Steinthorsson

A\&E Consulting, Inc., Westlake, Ohio 
Since its founding, NASA has been dedicated to the advancement of aeronautics and space science. The NASA Scientific and Technical Information (STI) Program Office plays a key part in helping NASA maintain this important role.

The NASA STI Program Office is operated by Langley Research Center, the Lead Center for NASA's scientific and technical information. The NASA STI Program Office provides access to the NASA STI Database, the largest collection of aeronautical and space science STI in the world. The Program Office is also NASA's institutional mechanism for disseminating the results of its research and development activities. These results are published by NASA in the NASA STI Report Series, which includes the following report types:

- TECHNICAL PUBLICATION. Reports of completed research or a major significant phase of research that present the results of NASA programs and include extensive data or theoretical analysis. Includes compilations of significant scientific and technical data and information deemed to be of continuing reference value. NASA's counterpart of peerreviewed formal professional papers but has less stringent limitations on manuscript length and extent of graphic presentations.

- TECHNICAL MEMORANDUM. Scientific and technical findings that are preliminary or of specialized interest, e.g., quick release reports, working papers, and bibliographies that contain minimal annotation. Does not contain extensive analysis.

- CONTRACTOR REPORT. Scientific and technical findings by NASA-sponsored contractors and grantees.
- CONFERENCE PUBLICATION. Collected papers from scientific and technical conferences, symposia, seminars, or other meetings sponsored or cosponsored by NASA.

- SPECIAL PUBLICATION. Scientific, technical, or historical information from NASA programs, projects, and missions, often concerned with subjects having substantial public interest.

- TECHNICAL TRANSLATION. Englishlanguage translations of foreign scientific and technical material pertinent to NASA's mission.

Specialized services that complement the STI Program Office's diverse offerings include creating custom thesauri, building customized data bases, organizing and publishing research results ... even providing videos.

For more information about the NASA STI Program Office, see the following:

- Access the NASA STI Program Home Page at http://www.sti.nasa.gov

- E-mail your question via the Internet to help@sti.nasa.gov

- Fax your question to the NASA Access Help Desk at 301-621-0134

- Telephone the NASA Access Help Desk at 301-621-0390

- Write to: NASA Access Help Desk NASA Center for AeroSpace Information 7121 Standard Drive Hanover, MD 21076 
NASA/CR-2002-211515

\title{
Computation of Turbulent Heat Transfer on the Walls of a 180 Degree Turn Channel With a Low Reynolds Number Reynolds Stress Model
}

\author{
A.A. Ameri \\ University of Toledo, Toledo, Ohio \\ D.L. Rigby \\ QSS Group, Inc., Cleveland, Ohio \\ E. Steinthorsson \\ A\&E Consulting, Inc., Westlake, Ohio
}

Prepared for the

Turbo Expo 2002

cosponsored by the American Society of Mechanical Engineers

and the International Gas Turbine Institute

Amsterdam, The Netherlands, June 3-6, 2002

Prepared under Cooperative Agreement NCC3-923

National Aeronautics and

Space Administration

Glenn Research Center 


\section{Acknowledgments}

This work was supported by the UEET program. The authors wish to express their gratitude to Dr. Raymond Gaugler, Chief, Turbine Branch, at the NASA Glenn Research Center, for his support of this work.

Available from

NASA Center for Aerospace Information 7121 Standard Drive

Hanover, MD 21076
National Technical Information Service 5285 Port Royal Road Springfield, VA 22100

Available electronically at http://gltrs.grc.nasa.gov/GLTRS 


\title{
COMPUTATION OF TURBULENT HEAT TRANSFER ON THE WALLS OF A 180 DEGREE TURN CHANNEL WITH A LOW REYNOLDS NUMBER REYNOLDS STRESS MODEL
}

\author{
A.A. Ameri \\ University of Toledo \\ Toledo, Ohio \\ D.L. Rigby \\ QSS Group, Inc. \\ Cleveland, Ohio \\ E. Steinthorsson \\ A\&E Consulting, Inc. \\ Westlake, Ohio
}

\begin{abstract}
The Low Reynolds number version of the Stress- $\omega$ model and the two equation $k-\omega$ model of Wilcox were used for the calculation of turbulent heat transfer in a 180 degree turn simulating an internal coolant passage. The Stress- $\omega$ model was chosen for its robustness. The turbulent thermal fluxes were calculated by modifying and using the Generalized Gradient Diffusion Hypothesis. The results showed that using this Reynolds Stress model allowed better prediction of heat transfer compared to the $\mathrm{k}-\omega$ two equation model. This improvement however required a finer grid and commensurately more CPU time.

\section{INTRODUCTION}

Our computational turbine heat transfer group has long been interested in developing the necessary tools to compute the external (blade surface) and internal (cooling passage) heat transfer. We have adopted the k- $\omega$ model of Wilcox [1] for its robustness and the absence of distance to the wall in its formulation. It was therefore natural for us to choose the Reynolds Stress model (RSM) based on the $\omega$ equation of Wilcox [1] for our first venture into this type of modeling.

We have in the past presented the solution to the problem of flow and heat transfer in a 180 degree channel[2] as predicted using the $\mathrm{k}-\omega$ model. The geometry and experimental measurements chosen come out of the work of Arts et al. [3]. In this work we will explore the use of the Stress- $\omega$ model and contrast the solutions using the two models.
\end{abstract}

The RSMs are good candidates for this effort due to the exactness of their production terms and their ability to better represent the flow history among other advantages. The exactness of the production terms among other advantages has the potential to better simulate the stagnation flow, reattachment and curvature effects. Advances in Reynolds Stress modeling are continuously being made. Much of the effort has been placed in the modeling of the pressure-strain correlation in these models which are of significant magnitude and are responsible for the redistribution between different components of the Reynolds Stress tensor. To make the correlations valid near walls many authors use the so called reflection terms which in most instances require the unit wall normals to the wall. These quantities are not always clearly definable away from walls and are thus not desirable. Some workers instead have tried to use various invariances of the anisotropy of Reynolds Stress matrix for this purpose [4]. It is not the intent of this paper to provide a comprehensive summary of RSMs and the interested reader may refer to [5] which is a recent review paper on this subject. More recently the method of elliptic relaxation which solves an additional set of six differential equations to modify the redistribution tensor in the vicinity of the walls has been gaining momentum[6]. The scheme has been applied to some two dimensional or axisymmetric cases [6-9], but has not yet been proven for three-dimensional complex problems. Due to the inclusion of six additional equations the computational cost is presumably much higher than the simpler alternative. 
There have been attempts made to solve the heat transfer problem in channels using RSMs. For example, Iacovides and Raisee[10], have performed internal cooling passage calculations with a Reynolds Stress Model. Iacovides, Launder and $\mathrm{Li}[4]$ also applied their RSM model to flow and heat transfer in a U bend. Recently Chen et al.[11,12] applied their $\varepsilon$ based RSM to an internal cooling channel heat transfer and achieved good results. The RSM model used in that work was reflection free and was applied all the way to the wall, although the distance to the wall was used in a damping function.

The present Stress- $\omega$ model is also valid all the way to the wall[1]. It does not use reflection terms and there is no need for wall functions or the use of a two layer model which have limited validity. This feature would make the model useful in heat transfer calculations. The model was implemented in our code Glenn-HT (NASA Glenn Heat Transfer Code) and solved using the code's explicit scheme.

\section{NOMENCLATURE}

$C_{p} \quad$ constant pressure specific heat

D hydraulic Diameter

$h$ heat transfer coefficient

$\mathrm{k} \quad$ Kinetic energy of turbulence

$\mathrm{Pr} \quad$ Prandtl number

Re Reynolds number

$T \quad$ static temperature/ $T_{0}$

$y^{+} \quad$ dimensionless distance from a wall, $=y \frac{\sqrt{\tau_{w} / \rho}}{v}$

$\varepsilon \quad$ Turbulence dissipation rate

$\gamma \quad$ specific heat ratio

$\tau \quad$ Reynolds stress

$\omega \quad$ Specific dissipation rate of turbulence

\section{Subscripts}

$\begin{array}{ll}\mathrm{t} & \text { total conditions } \\ \mathrm{w} & \text { wall value }\end{array}$

\section{FORMULATION}

\section{Stress-Omega Model}

As described in the introduction the Stress- $\omega$ Reynolds Stress model of Wilcox was adopted for the present work. The equations for the Reynolds stresses $\tau_{i j}=-\rho{\overline{u_{i}}}_{j}$ are given below:

$$
\begin{gathered}
\frac{\partial \tau_{i j}}{\partial t}+U_{k} \frac{\partial \tau_{i j}}{\partial x_{k}} \\
=-\tau_{i k} \frac{\partial U_{j}}{\partial x_{k}}-\tau_{j k} \frac{\partial U_{i}}{\partial x_{k}}-\underline{\rho \varepsilon_{i j}}-\underline{\Pi_{i j}}+\frac{\partial}{\partial x_{k}}\left[\mu \frac{\partial \tau_{i j}}{\partial x_{k}}+\underline{\rho C_{i j k}}\right]
\end{gathered}
$$

where the terms underlined on the right hand side are modeled.

The Stress- $\omega$ model uses the 'standard' modeling practice for the underlined terms except for the last term.

From the Kolmogorov hypothesis of local isotropy.

$$
\varepsilon_{i j}=\frac{2}{3} \varepsilon \delta_{i j}
$$

Using the definition of $\varepsilon=\beta_{0}^{*} \omega k$ allowing for 'isotropic damping' near walls,

$$
\varepsilon_{i j}=\frac{2}{3} \beta_{0}^{*} \omega k \delta_{i j}
$$

The term $\Pi_{i j}$ is the pressure-strain Correlation of LaunderReece and Rodi(1975)[16] written as:

$$
\begin{aligned}
& \Pi_{i j}=\beta^{*} C_{1} \omega\left(\tau_{i j}+\frac{2}{3} \rho k \delta_{i j}\right)-\hat{\alpha_{\infty}}\left(P_{i j}-\frac{2}{3} P \delta_{i j}\right) \\
& -\hat{\beta_{\infty}}\left(D_{i j}-\frac{2}{3} P \delta_{i j}\right)-\hat{\gamma_{\infty}} \rho k\left(S_{i j}-\frac{2}{3} S_{k k} \delta_{i j}\right)
\end{aligned}
$$

where

$$
\begin{gathered}
P_{i j}=\tau_{i m} \frac{\partial U_{j}}{\partial x_{m}}+\tau_{j m} \frac{\partial U_{i}}{\partial x_{m}}, \quad D_{i j}=\tau_{i m} \frac{\partial U_{m}}{\partial x_{j}}+\tau_{j m} \frac{\partial U_{m}}{\partial x_{i}} \\
\text { and } \\
P=\frac{1}{2} P_{k k}
\end{gathered}
$$

also

$$
C_{i j k}=\left[\sigma * \mu_{T} \frac{\partial \tau_{i j}}{\partial x_{k}}\right]
$$

For calculation of $\omega$ the standard equation is used [1]:

$$
\rho \frac{\partial \omega}{\partial t}+\rho U_{j} \frac{\partial \Phi}{\partial x_{j}}=\alpha \rho \omega / k \tau_{i j} \frac{\partial U_{i}}{\partial x_{k}}-\beta \rho \omega^{2}+\frac{\partial}{\partial x_{k}}\left[\left(\mu+\sigma \mu_{T}\right) \frac{\partial \omega}{\partial x_{k}}\right]
$$

above

$$
v_{T}=\alpha * \frac{k}{\omega} \quad \text { and } \quad R e_{T}=\frac{k}{\omega v}
$$

The closure coefficients are given as

$$
\begin{gathered}
\alpha^{*}=\frac{\alpha_{0}^{*}+R e_{T} / R_{k}}{1+R e_{T} / R_{k}} \\
\alpha=\frac{13}{25} \cdot \frac{\alpha_{0}+R e_{T} / R_{\omega}}{1+R e_{T} / R_{\omega}} \cdot \frac{3+R e_{T} / R_{\omega}}{3 \alpha_{0}^{*}+R e_{T} / R_{k \omega}} \\
\beta^{*}=0.09 \cdot \frac{4 / 15+R e_{T} / R_{\beta}}{1+\left(R e_{T} / R_{\beta}\right)} \cdot f_{\beta^{*}}
\end{gathered}
$$




$$
\begin{aligned}
& \hat{\alpha}=\frac{1 .+\hat{\alpha}_{\infty} R e_{T} / R_{k}}{1+R e_{T} / R_{k}} \\
& \hat{\beta}=\hat{\beta}_{\infty} \cdot \frac{R e_{T} / R_{k}}{1+R e_{T} / R_{k}} \\
& \hat{\gamma}=\hat{\gamma}_{\infty} \frac{\hat{\gamma}_{0}+R e_{T} / R_{k}}{1+R e_{T} / R_{k}} \\
& C_{1}=\frac{9}{5} \cdot \frac{5 / 3+R e_{T} / R_{k}}{1+R e_{T} / R_{k}}
\end{aligned}
$$

where the constants with the $\infty$ subscript are the constants of the original LRR model for the pressure-strain correlation model given as follows:

$$
\begin{gathered}
\hat{\alpha}_{\infty}=\left(8+C_{2}\right) / 11 \quad, \quad \hat{\beta}_{\infty}=\left(8 C_{2}-2\right) / 11 \quad \text { and } \\
\hat{\gamma}_{\infty}=\left(60 C_{2}-4\right) / 55 \\
\beta=\frac{9}{125} f_{\beta} \quad, \quad \sigma^{*}=\sigma=\frac{1}{2}, C_{2}=\frac{13}{25} \\
\alpha_{0}^{*}=\frac{1}{3} \beta_{0}, \alpha_{0}=0.105 \quad, \quad \hat{\gamma}_{0}=0.007 \\
R_{k}=R_{\beta}=12 \text { and } R_{\omega}=6.20
\end{gathered}
$$

Further definitions follow:

$$
\begin{gathered}
f_{\beta}=\frac{1+70 \chi_{\omega}}{1+80 \chi \omega} \quad, \quad \chi_{\omega}=\left|\frac{\Omega_{i j} \Omega_{j k} S_{k i}}{\left(\beta_{0}^{*} \omega\right)^{3}}\right| \quad \beta_{0}^{*}=0.09 \\
f_{\beta^{*}}=1 \text {, if } \chi_{k} \leq 0 \quad \text { and } \\
f_{\beta^{*}}=\frac{1 \div 640 \chi 2_{k}}{1 \div 400 \chi \chi_{k}} \text {, if } \chi_{k}>0 \\
\text { where } \quad \chi_{k}=\frac{1}{\omega 3} \frac{\partial k}{\partial x_{j}} \frac{\partial \omega}{\partial x_{j}}
\end{gathered}
$$

\section{K- $\omega$ model}

The k- $\omega$ turbulence model of Wilcox [1] is used to model the effects of the small scales of turbulence on the larger scales of the mean flow. The version of the model used here incorporates some improvements suggested by Menter (1993)[17]. Using the original formulation of Wilcox, the model equations can be written as follows:

$$
\rho \frac{\partial k}{\partial t}+\rho U_{j} \frac{\partial k}{\partial x_{j}}=\mu_{T} \Omega^{2}-\rho \beta^{*} \omega k+\frac{\partial}{\partial x_{j}}\left[\left(\mu+\sigma \mu_{T}\right) \frac{\partial k}{\partial x_{j}}\right]
$$

$$
\rho \frac{\partial \omega}{\partial t}+\rho U_{j} \frac{\partial \omega}{\partial x_{j}}=\alpha \alpha^{*} \Omega^{2}-\beta \rho \omega^{2}+\frac{\partial}{\partial x_{j}}\left[\left(\mu+\sigma \mu_{T}\right) \frac{\partial \omega}{\partial x_{j}}\right]
$$

The isotropic eddy viscosity is given by

$$
\mu_{t}=\alpha * \rho \frac{k}{\omega}
$$

Finally, in the original model the coefficients appearing in the model are the following:

$$
\begin{gathered}
\sigma=0.5, \quad \beta=\frac{3}{40}, \beta^{*}=0.09 f_{\beta} \\
f_{\beta}=\frac{5 / 18+\left(R e_{T} / R_{\beta}\right)^{4}}{1+\left(R e_{T} / R_{\beta}\right)^{4}} \\
f_{\alpha}=\frac{\alpha_{0}+\left(R e_{T} / R_{\omega}\right)}{1+\left(R e_{T} / R_{\omega}\right)} \\
f_{\mu}=\frac{\alpha_{0}+\left(R e_{T} / R_{K}\right)}{1+\left(R e_{T} / R_{K}\right)}
\end{gathered}
$$

in the above

$$
\alpha_{0}=1, \alpha^{*}=0.025, R_{k}=6, R_{\omega}=2.7
$$

Following the suggestions of Menter [17], the production terms are modified and written in terms of vorticity magnitude $\Omega$ This reduces the overshoots of heat transfer rates in the vicinity of stagnation points.

\section{Turbulent Heat Flux}

Both models integrates to the walls and no wall functions are used. A value for Prandtl number (Pr) equal to 0.72 is used. Viscosity is a function of temperature through a 0.7 power law [18] and $C p$ is taken to be a constant.

When using the 2-equation model for the calculation of turbulent thermal fluxes, eddy viscosity model and a constant value of 0.9 for turbulent Prandtl number, $P r_{t}$ was used. For the Reynolds stress model the turbulent heat fluxes were calculated using the Generalized Gradient Diffusion Hypothesis (GGDH) given in for example Iacovides et. al. [3] among other places.

$$
-\overline{u_{i} \theta^{\prime}} \alpha \overline{u_{i} u} \frac{k}{k} \frac{\partial \bar{\theta}}{\partial x_{j}}
$$

For our purposes we will rewrite the above in the following form

$$
-\overline{u_{i} \theta^{\prime}} \alpha \frac{\overline{u_{i} u_{j}}}{k} \frac{k}{\varepsilon} \frac{\overline{\partial \theta}}{\partial x_{j}}
$$

rewriting using $\mathrm{k}$ and $\omega$, we found the following form 
satisfactory for flow over flat plates.

$$
-\overline{u_{i} \theta^{\prime}}=3.3 v_{T} \frac{\overline{u_{i} u_{j}}}{k} \frac{\overline{\partial \theta}}{\partial x_{j}}
$$

The ratio of $\frac{k}{\overline{u_{i} u_{j}}}$ can be regarded as an anisotropic turbulent Prandtl number relating an anisotropic thermal diffusivity to an isotropic momentum diffusivity.

Using the eddy viscosity hypothesis with a constant Prandtl number in Stress- $\omega$ model as is done for the k- $\omega$ model produced heat transfer results that were too low. This was found to be due to the fact that the Stress- $\omega$ model produces lower levels of $\mathrm{k}$ than does the $\mathrm{k}-\omega$ model.

\section{CHANNEL GEOMETRY AND FLOW CONDITIONS}

The test problem was taken from the experiment of Arts et al.[6] It is an aggressive 180 degree turn channel with a rectangular cross section. The inlet and exit channels have the same cross section as shown in Fig. 1. The overall length of the channel is $8 \mathrm{~W}$. The divider has a thickness of W/5 and extends to within one width of the end wall. The divider has a semicircular end. The experiments were performed for two channels with aspect ratios $(\mathrm{H} / \mathrm{W})$ of 1 . and 0.5 , the latter of which is considered here. The condition of symmetry has been used so that only half of the channel has been gridded. In the experimental work two Reynolds Numbers were considered, namely 17,000 and 35,000. For the present numerical work the channel Reynolds number of 17000 was simulated.

\section{COMPUTATIONAL METHOD}

\section{Computational Scheme}

The simulations in this study were performed using a multiblock computer code called Glenn-HT [2]. This code is a general purpose flow solver designed for simulations of flows in complicated geometries. The code solves the full compressible, Reynolds-averaged Navier-Stokes equations using a multi-stage Runge-Kutta-based multigrid method. It uses the finite volume method to discretize the equations. The code uses central differencing together with artificial dissipation to discretize the convective terms. The overall accuracy of the code is second order. To achieve good convergence the turbulence $\omega$ equation and the Reynolds stresses were implicitly coupled in a pointwise fashion in the Runge-Kutta stage calculations.

\section{Boundary Conditions}

Boundary condition treatment is dealt with in [2]. Here we will not repeat the treatment of standard flow variables but extend the discussion to include specification of Reynolds stresses. The boundaries are treated as follows.

Inlet: At the inlet, the incoming profiles of $\mathrm{k}$ and $\omega$ need to be specified. Typically, the details of the profiles are unknown so

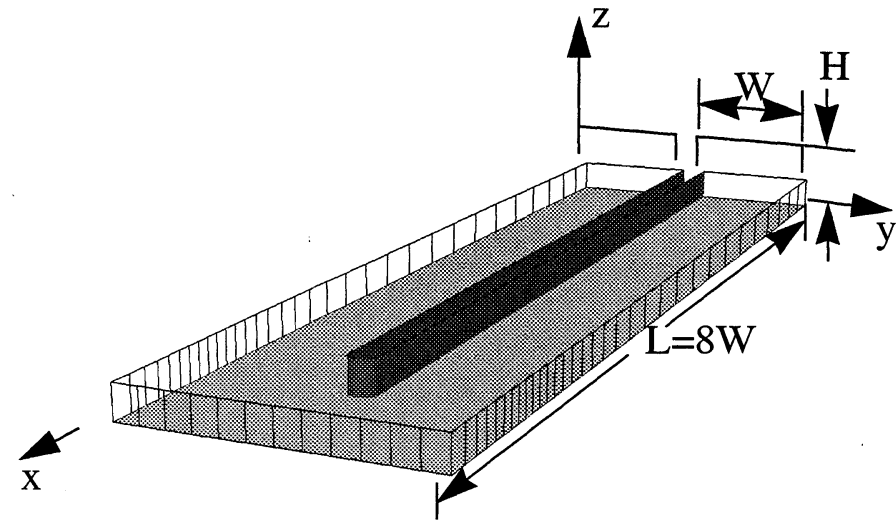

Figure 1.Sketch of the geometry

reasonable assumptions need to be made. Approximate values of $\mathrm{k}$ and $\omega$ can be computed based on turbulence intensity and some measure of a length scale. In cases such as the present where the flow is sensitive to the exact values of $\mathrm{k}$ and $\omega$ at the inlet, the profiles need to be specified more carefully.

In the present problem the channel is extended upstream of where the inlet boundary condition is specified and heating begins. For that reason an inlet profile corresponding to a fully developed channel flow is assumed. For the k- $\omega$ model this specification is done algebraically [2]. For the case where the detailed boundary conditions on the Reynolds stresses are necessary the approach taken was to solve the fully developed channel flow and transfer the resulting profile to the inlet of the 180 degree channel. The problem was solved on a grid identical to the grid used at the inlet but extended in the axial direction. The channel was not very long so in order to achieve fully developed flow, compressible flow periodicity in axial direction was enforced.

Exit: The static pressure is specified at the exit and other variables are extrapolated.

Symmetry: Symmetry boundary conditions are trivial for all the variables except the Reynolds stresses some of which vanish and others have a vanishing normal derivative to the symmetry plane.

Walls: At solid walls the specific dissipation rate, $\omega$, can be specified as follows:

$$
\omega=\left.S_{R} \frac{\partial}{\partial \boldsymbol{n}}(u)\right|_{\text {wall }}
$$

where

$$
S_{R}=\left\{\begin{array}{c}
\left(\frac{50}{K_{R}}\right)^{2} \text { if } K_{R}<25 \\
\frac{100}{K_{R}} \text { if } K_{R}>25
\end{array}\right.
$$

and $K_{R}$ is equivalent sand-grain roughness height in turbulent 

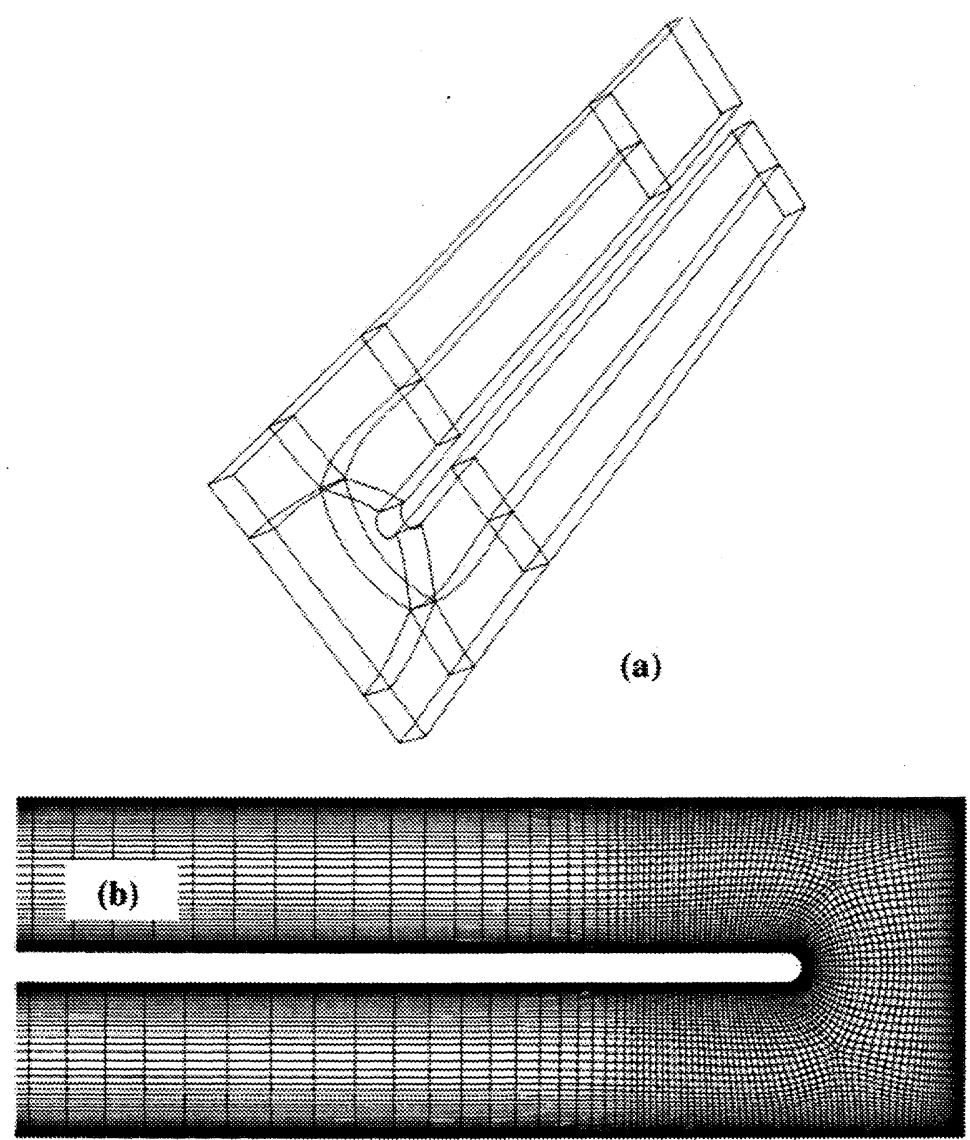

(c)
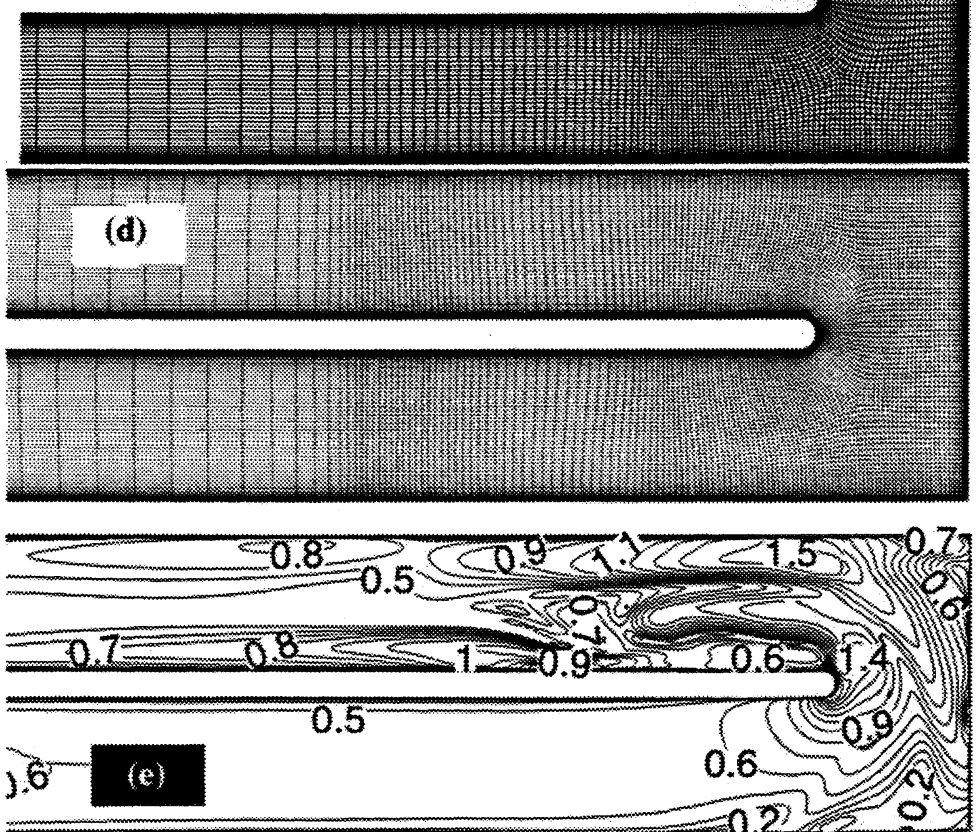

Figure 2.(a) Grid Topology (b) Coarse Grid, (c) Medium Grid and (d) Fine Grid and (e) distribution of $y+$ for grid ' $(d)$ '
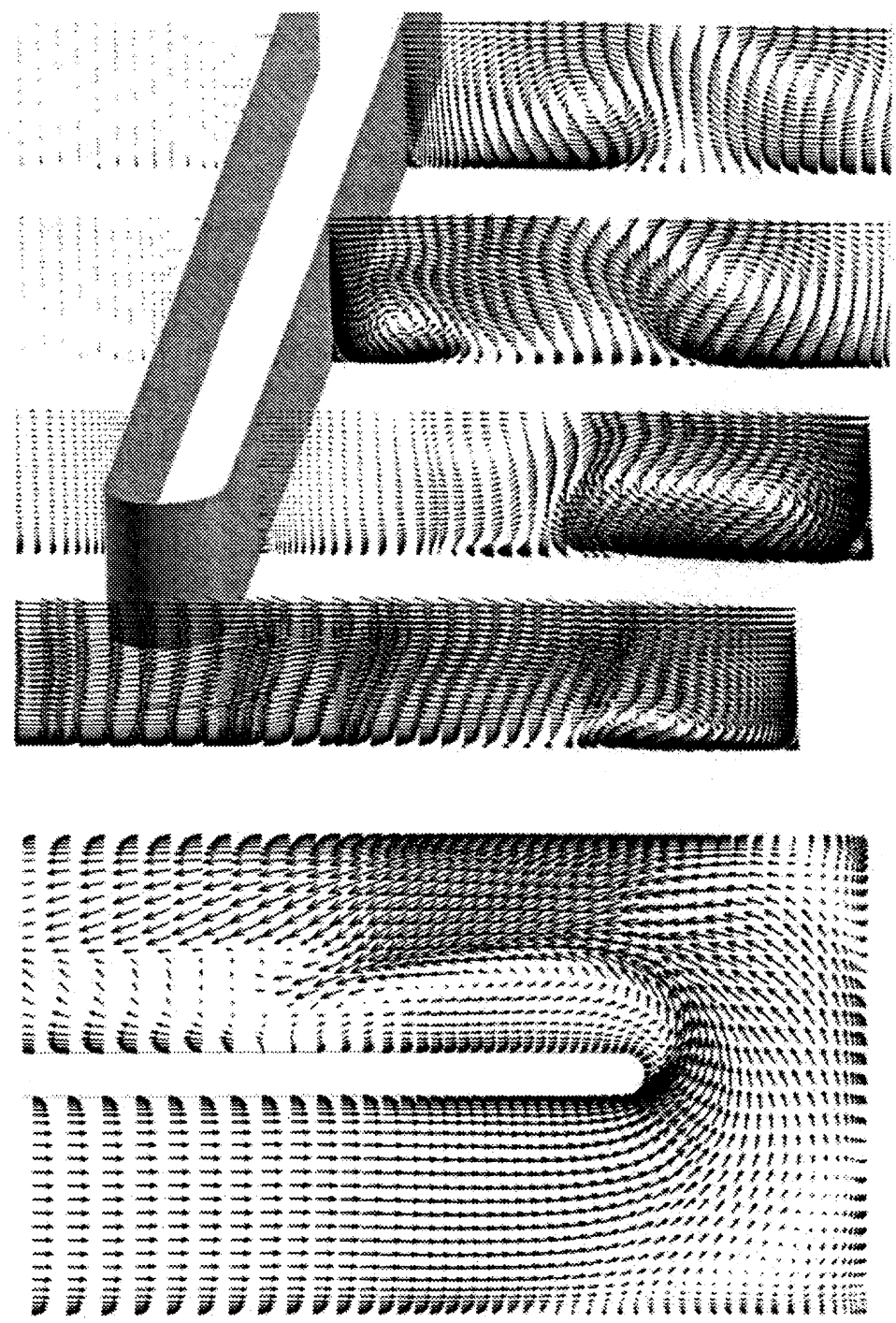

Figure 3. Velocity vectors (a) Downstream of the turn and (b) near the bottom wall and (c) Streamline tracing the major vortices in the flow.

wall units. Typically, $K_{R}=5$ is chosen, corresponding to a hydraulically smooth surface.

The wall temperature is specified as a constant value for heat transfer surfaces. The Reynolds stresses and the turbulent Thermal fluxes are zero at the walls.

\section{GEOMETRY MODELING AND GRID SYSTEM}

Figure 1 shows a typical grid topology and the grid constructed for this problem. It covers half of the channel and a symmetric boundary condition is used. The multiblock grid generated using a commercial package called GridPro, consists approximately $.34 \mathrm{E} 6, .52 \mathrm{E} 6$ and $1.06 \mathrm{E} 6$ cells for the coarse, medium and the fine grid. Grid spacing adjacent to the walls produce averaged dimensionless spacing $(y+)$ near unity (Fig. 2(e) corresponding to grid "(d)') with a stretching ratio of grid 
spacing away from the walls equal to 1.1 for the fine grid and 1.2 for the medium and coarse grid calculation.

\section{RESULTS AND DISCUSSION}

In an earlier paper [2] we reported our flow and heat Iransfer solution for the present problem using the $\mathrm{k}-\omega$ model. The calculations for that model were repeated here for the sake of comparison of heat transfer results. The result was identical to that presented here (as expected) but the grid was 3.5 times coarser than the present Medium grid.

Figure 3 shows the details of the flow downstream of the turn and very near the bottom wall of the channel as predicted with the Reynolds Stress model on the fine grid. The simulations show that the flow around the corner is quite complex. Fig 3(a) shows the multiple vortices generated in the turn as Fig. 3(b) show the complex flow structure near the bottom wall. One can discern a large vortex at the inner wall of the turn with its axis generally in the normal to the bottom wall direction. There is another vortex that starts near the inner turn and generally follows the flow direction. This vortex is accompanied by an opposing one on the other side of the plane of symmetry. One can discern also a corner vortex on the inner wall of the return leg with its axis in the flow direction. Other vortical structures are also present as evidenced by Figure 3 .

\section{Heat Transfer}

Figure 4(a) shows the experimental measurement of the rate of heat transfer on the bottom wall in terms of a Nusselt number ratio $\mathrm{Nu} / \mathrm{Nu}_{0}$. The data is from the experimental meastrements of Arts et al. [16] and corresponds to an aspect ratio of 0.5 and Reynolds number of 18000 . The contours are Nusselt number ratio $\mathrm{Nu} / \mathrm{Nu} 0$, where

$$
N u=\frac{h D}{k}
$$

In this equation $D$ is the hydraulic diameter and $k$ is the thermal conductivity evaluated at the reference temperature $T_{\text {ref }}$ defined as the arithmetic average of the inlet and exit centerline temperatures. The heat transfer coefficient $h$ is defined by the following expression:

$$
h=\frac{q_{w}}{T_{w}-T_{r e f}}
$$

$\mathrm{Nu}_{0}$ is the Nusselt number for a fully developed channel flow defined as:

$$
N u_{0}=0.023 \operatorname{Re}_{D}{ }_{P r}^{0.8}
$$

Figure $4 \mathrm{~b}$ shows the calculated heat transfer rate using the $\mathrm{k}$ - $\omega$ model. This was accomplished using the coarse grid.

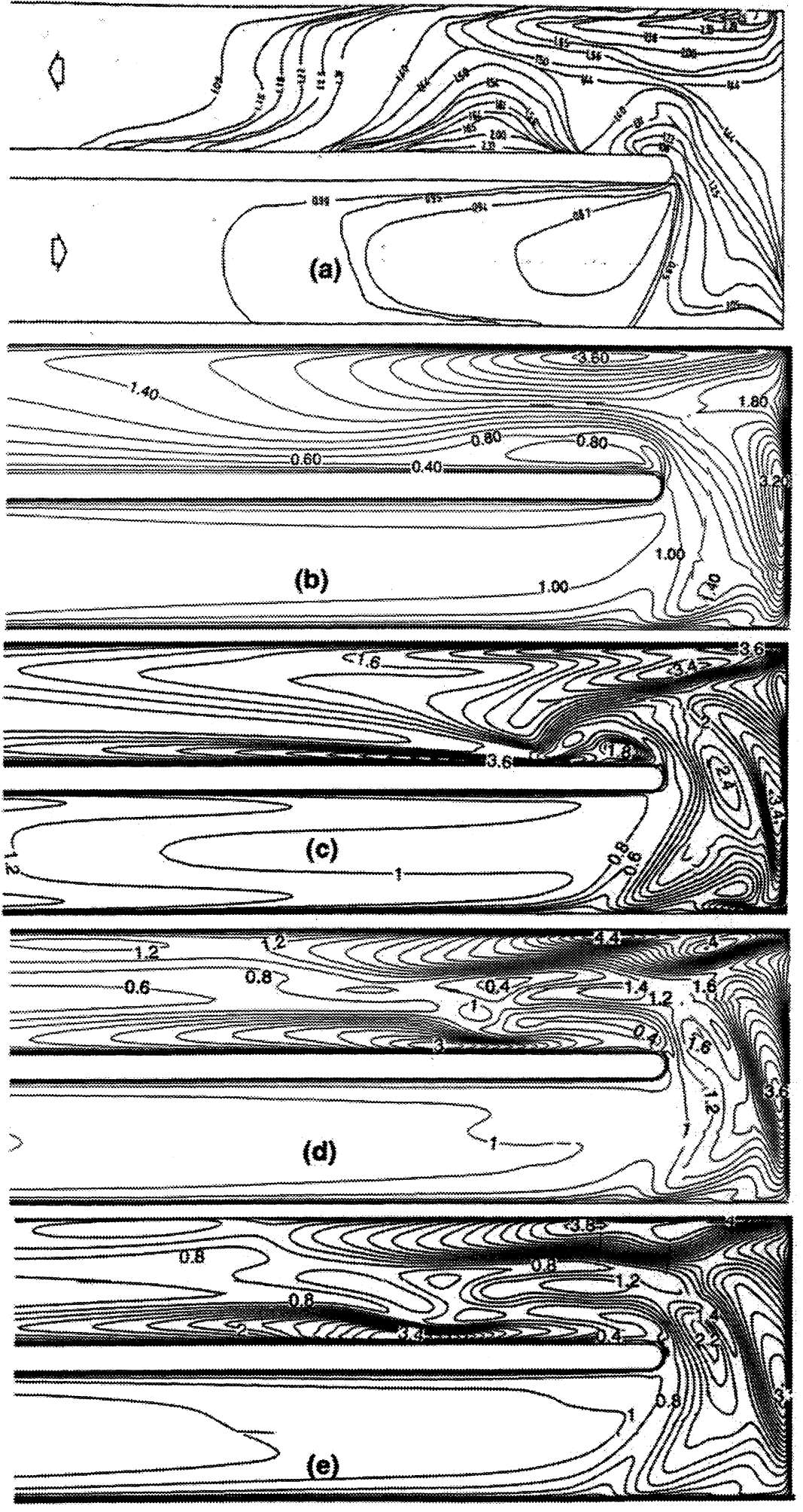

Figure 4.Nu/NuO for the case of channel fow with $A R=0.5$ and Red=17000. (a) Experimental measurement of Arts et all[16], (b) calculation using $\mathrm{k}-\omega$ model and $(\mathrm{c})$, (d) and (e) calculation using Stress$\omega$ model with the $340,000,523,000$ and $1.06 \mathrm{E} 6$ cells. 
The results are similar to those obtained with a yet coarser grid $(\sim 100,000$ cells) in [2] and thus it is ensured that further refinement would not change the character of the solution substantially. The results have two major differences with the data. First the rise in the rate of heat transfer near the endwall (the wall facing the inlet) is not matched by the experiment and secondly the rise in heat transfer near the inner wall of the return leg is not captured by the $\mathrm{k}-\omega$ model.

Figure 4(c) shows the same case solved using the Stress- $\omega$ model and the coarse grid of 340,000 cells while Fig. 4(d) is for the medium grid of 523,000 cells. As can be seen there are substantial differences between the two solutions. This suggested that further refinement was still necessary. A finer grid of $1.06 \mathrm{E} 6$ cells was considered. The solutions using RSM have similar characteristics. Namely a rise in heat transfer near the endwall as with the k- $\omega$ model, not supported by the experiment and the two other regions of high heat transfer on the return leg. The high heat transfer region on the return leg adjacent to the partition is captured by the RSM. The rise in heat transfer on the return leg near the outer wall is present for the Stress- $\omega$ model as for the $\mathrm{k}-\omega$ model in agreement with the experimental data.

It is observed therefore that the Reynolds Stress model utilized can help capture the flow physics and by extension the rate of heat transfer better than the two-equation model version. A much finer grid is required in order to obtain a satisfactory solution with the RSM. In the present case the coarsest grid to capture the physics of the flow with the RSM was 3 times finer than the grid used for the $\mathrm{k}-\omega$ model in [2]. The expenditure however appears to be worthwhile if a greater resolution of the heat transfer distribution is desired. In the present case however the agreement with measurements in the U-turn area suggests that the present model is still not quite able to predict the turbulence levels where there exists flow acceleration and impingement. It should be noted that the present problem owing to the severe turn in the flow and presence of severe three-dimensionality and strong secondary flows is a difficult test for any turbulence model.

\section{SUMMARY AND CONCLUSIONS}

The Low Reynolds number versions of Stress- $\omega$ model and the two equation $\mathrm{k}-\omega$ model of Wilcox were used for the calculation of turbulent heat transfer in a 180 degree turn simulating an internal coolant passage. The RSM was implemented within a Finite Volume code (Glenn-HT) and solved using the existing explicit scheme. For the present problem care was taken to specify reasonable inlet boundary conditions for all the variables, especially those for the Reynolds stresses by first solving a fully developed flow in a channel.

A rather systematic grid study was implemented. The results showed that using the Reynolds Stress model allowed better prediction of heat transfer compared to the $\mathrm{k}-\omega$ two equation model. This improvement however required specification of a finer grid and a larger CPU time.

\section{REFERENCES}

[1] Wilcox, D. C., 1998, Turbulence Modeling for CFD, Second Edition, DCW Industries, Inc. La Canada, CA.

[2] Rigby, D.L., Ameri, A. A. and Steinthorsson, E., 'Internal Passage Heat Transfer Predictions Using Multiblock Grids and a k- $\omega$ Turbulence Model," ASME paper, 96-GT-188.

[3] Arts, T., Lambert de Rouvroit, M., Rau, G. and Acton, P, 1992, "Aero-Thermal Investigation of the Flow Developing in a 180 Degree Turn Channel,", In "Heat Transfer in Turbomachinery," edited by Goldstein; Leontiev; Metzger, Begell House, 1994 and VKI pre-print No 1992-10.

[4] Iacovide, H., Launder, B.E., and Li, H.-Y., 'Application of a Reflection-Free DSM to Turbulent Flow and Heat Transfer in a Square-Sectioned U-Bend,' Experimental Thermal and Fluid Science 1996: 13:419-429.

[5] Hanjalic, K., 1999, 'Second-Moment Turbulence Closures for CFD: Needs and Prospects,' International Journal of Computational Fluid Dynamics, Vol. 12, pp.67-97.

[6] Durbin, Paul, 'A Reynolds Stress Model for Near-Wall Turbulence,' J. Fluid Mech.(1993), vol. 249, pp. 465-498.

[7] Manceau, R. and Hanjalic, K., 'A new form of the elliptic relaxation equation to account for wall effects in RANS modeling', Physics of Fluids, 2000, Vol. 12 No. 9 pp. 23452351.

[8] Dutzler, G.K., Petterson-Reif, B.A. and Andersson, H.I., 'Relaminarization of turbulent flow in entrance region of rapidly rotating channel', International Journal of Heat and Fluid Flow, 2000, Vol. 21, pp. 49-57.

[9] Wizman, V., Laurence, D., Kanniche, M., Durbin, P. and Demuren, A., 1996, 'Modeling of near-wall effects in Secondmoment closures by elliptic relaxation,' International Journal of Heat and Fluid Flow, Vol. 17, pp. 255-266.

[10] Iacovides, H. and Raisee, M., 1999, "Recent Progress in the Computation of Flow and Heat Transfer in Internal Cooling Passages of Turbine Blades,' International Journal of Heat and Fluid Flow, Vol. 20, 320-328.

[11] Hamn-Ching Chen, Yong-Jun Jang, and Je-Chin Han, 2000, 'Near-Wall Second-Moment Closure for Rotating Multiple-Pass Cooling Channels,', Journal of Thermophysics and Heat Transfer, Vol. 14, No. 2, April-June 2000.

[12] Hamn-Ching Chen, Yong-Jun Jang and Je-Chin Han, 1999, 'Computation of Flow and Heat Transfer in Rotating Two-Pass Square Channels by a Reynolds Stress Model,' ASME paper, $99-$ GT-174.

[13] Steinthorsson, E., Liou, M. S., and Povinelli, L.A., 1993, "Development of an Explicit Multiblock/Multigrid Flow Solver for Viscous Flows in Complex Geometries," AIAA-93-2380. 
[14] Arnone, A., Liou, M.S., and Povinelli, L. A., 1991, "Multigrid Calculation of Three Dimensional Viscous Cascade Flows", AIAA Paper 91-3238.

[15] "GRIDPRO, ${ }^{\mathrm{TM}} / \mathrm{az} 3000$, Users Guide and Reference Manual", 1993, Program Development Corporation, White Plains, NY.

[16] Launder, B. E., Reece, G. J. and Rodi, W., 1975, "Progress in the Development of a Reynolds Stress Turbulence Closure," Journal of Fluid Mechanics, Vol. 68, Pt.3, pp. 537-566.

[17] Menter, Florian R., 1993, “Zonal Two-Equation k- $\omega$ Turbulence Models for Aerodynamic Flows," AIAA-93-2906.

[18] Schlichting, H. Boundary Layer Theory. McGraw-Hill, New York, seventh ed. pp. 312-313. 
Public reporting burden for this collection of information is estimated to average 1 hour per response, including the time for reviewing instructions, searching existing data sources, gathering and maintaining the data needed, and completing and reviewing the collection of information. Send comments regarding this burden estimate or any other aspect of this collection of information, including suggestions for reducing this burden, to Washington Headquarters Services, Directorate for Information Operations and Reports, 1215 Jefferson Davis Highway, Suite 1204, Arlington, VA 22202-4302, and to the Office of Management and Budget, Paperwork Reduction Project (0704-0188), Washington, DC 20503.

\begin{tabular}{|l|l|l}
\hline 1. AGENCY USE ONLY (Leave blank) & $\begin{array}{c}\text { 2. REPORT DATE } \\
\text { April } 2002\end{array}$ & $\begin{array}{r}\text { 3. REPORT TYPE AND DATES COVERED } \\
\text { Final Contractor Report }\end{array}$ \\
\hline
\end{tabular}

4. TITLE AND SUBTITLE

5. FUNDING NUMBERS

Computation of Turbulent Heat Transfer on the Walls of a 180 Degree Turn

Channel With a Low Reynolds Number Reynolds Stress Model

6. AUTHOR(S)

WU-714-03-50

NCC3-923

A.A. Ameri, D.L. Rigby, and E. Steinthorsson

7. PERFORMING ORGANIZATION NAME(S) AND ADDRESS(ES)

8. PERFORMING ORGANIZATION

REPORT NUMBER

University of Toledo

Toledo, Ohio 43606

E-13308

9. SPONSORING/MONITORING AGENCY NAME(S) AND ADDRESS(ES)

10. SPONSORING/MONITORING AGENCY REPORT NUMBER

National Aeronautics and Space Administration

Washington, DC 20546-0001

NASA CR-2002-211515

GT-2002-30211

\section{SUPPLEMENTARY NOTES}

Prepared for the Turbo Expo 2002 cosponsored by the American Society of Mechanical Engineers and the International Gas Turbine Institute, Amsterdam, The Netherlands, June 3-6, 2002. A.A. Ameri, University of Toledo, Toledo, Ohio; D.L. Rigby, QSS Group, Inc., Cleveland, Ohio; and E. Steinthorsson, A\&E Consulting, Inc., Westlake, Ohio. Project Manager, Turbomachinery and Propulsion Systems Division, NASA Glenn Research Center, Raymond Gaugler, organization code 5820, 216-433-5882.

12a. DISTRIBUTION/AVAILABILITY STATEMENT

12b. DISTRIBUTION CODE

Unclassified - Unlimited

Subject Categories: 05, 07 and 34

Distribution: Nonstandard

Available electronically at http://gltrs.grc.nasa.gov/GLTRS

This publication is available from the NASA Center for AeroSpace Information, 301-621-0390.

13. ABSTRACT (Maximum 200 words)

The Low Reynolds number version of the Stress- $\omega$ model and the two equation k- $\omega$ model of Wilcox were used for the calculation of turbulent heat transfer in a 180 degree turn simulating an internal coolant passage. The Stress- $\omega$ model was chosen for its robustness. The turbulent thermal fluxes were calculated by modifying and using the Generalized Gradient Diffusion Hypothesis. The results showed that using this Reynolds Stress model allowed better prediction of heat transfer compared to the $\mathrm{k}-\omega$ two equation model. This improvement however required a finer grid and commensurately more CPU time.

14. SUBJECT TERMS

Turbomachinery; Gas turbine; Heat transfer; Reynolds stress modeling

15. NUMBER OF PAGES

17. SECURITY CLASSIFICATION
OF REPORT
Unclassified

18. SECURITY CLASSIFICATION
OF THIS PAGE
Unclassified

\section{SECURITY CLASSIFICATION OF ABSTRACT \\ Unclassified}

14

16. PRICE CODE 